\title{
A Study on the Transformer Design considering the Inrush Current Reduction in the Arc Welding Machine
}

\author{
In-Gun Kim ${ }^{1}$, Huai-Cong Liu ${ }^{1}$, Su-Yeon $\mathrm{Cho}^{2}$, and $\mathrm{Ju} \mathrm{Lee}^{1 *}$ \\ ${ }^{1}$ Department of Electrical Engineering Hanyang University, Seoul 04763, Korea \\ ${ }^{2}$ Korea Automotive Technology Institute(KATECH), Cheon-an 31214, Korea
}

(Received 9 March 2016, Received in final form 21 April 2016, Accepted 27 April 2016)

\begin{abstract}
The transformer used in an inverter type arc welding machine is designed to use high frequency in order to reduce its size and cost. Also, selecting core materials that fit frequency is important because core loss increases in a high frequency band. An inrush current can occur in the primary coil of transformer during arc welding and this inrush current can cause IGBT, the switching element, to burn out. The transformer design was carried out in $A_{P}$ method and amorphous core was used to reduce the size of transformer. In addition, sheet coil was used for primary winding and secondary winding coil considering the skin effect. This paper designed the transformer core with an air gap to prevent IGBT burnout due to the inrush current during welding and proposed the optimum air gap length.
\end{abstract}

Keywords : arc welding machine, ferrite \& amorphous core, inrush current, air gap core

\section{Introduction}

Recent inverter arc welding machine systems can have high speed switching by using high performance switching elements and are controlled in high frequency. Power IC and circuit, transformer, and reactor for switching take up the largest volume among the components of arc welding machine. Therefore, since the capacity of transformer and reactor is inversely proportional to frequency, it is necessary to operate them in high frequency $[1,2]$.

Since the capacity of transformer is influenced by magnetic flux density value and the magnetic flux density is determined by core materials, selecting appropriate materials is important. In general, the core materials that are usable in a high frequency band are ferrite, amorphous. When they have the same capacity, the differences of two materials are magnetic flux density, production cost, core loss, etc. This paper designed the transformer based on the information mentioned above.

1) The basic design of transformer was carried out using the $A_{P}$ method.

2) The secondary winding coil was formed in a parallel circuit as it has low voltage and high current.

CThe Korean Magnetics Society. All rights reserved.

*Corresponding author: Tel: +82-2-2220-0342

Fax: +82-2-2295-7111, e-mail: julee@hanyang.ac.kr
3) PSP coil and sheet coil were used for coil method considering the skin effect and proximity effect.

4) To minimize the size of transformer core, it was made in different materials (ferrite and amorphous) and then compared.

Due to the nature of welding machine, when the transformer core is saturated after the welding rod is in touch with a base metal, then a high current above 1000A flows in the primary winding of transformer. This current is called inrush current and the power IC can be burned out due to the inrush current. Thus, it is important to choose the core size of transformer considering the inrush current during design. The methods to prevent inrush current are as follows.

1) Make the size of core big so that the transformer is not saturated.

2) Maintain the size of transformer core as it is and increase the number of the turns of coil instead.

This paper uses an air gap to prevent the saturation of core while maintaining the size and number of turns of core $[3,4]$.

\section{Transformer Design Method for Welding Machine}

\subsection{Area Product Design}

$A_{P}$ design method is one of the methods of transformer 

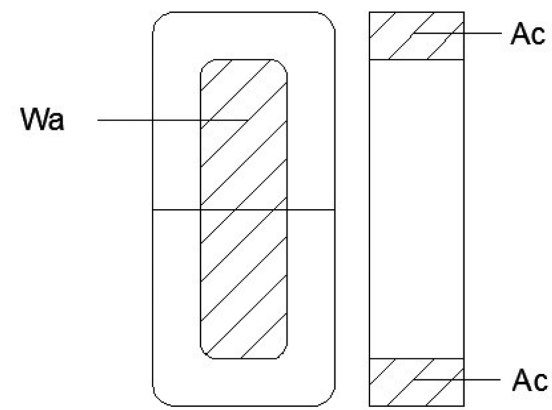

Fig. 1. $A_{P}$ Design Method.

design and is expressed by the multiplication of $W_{a}$ and $A_{c}$. $A_{P}$ method can be expressed in formula 1 , formula 2 , and Fig. 1. The standard for determining the area of $W_{a}$ depends on the core shape. $A_{P}$ design method can be shown as in Fig. 1 [5-7].

$$
\begin{aligned}
& A_{P}=W_{a} \times A_{c} \\
& A_{P}=\left(P_{t} \times 10^{4}\right) /\left(B_{m} \times f \times J \times K_{f} \times K_{u}\right)
\end{aligned}
$$

The $P_{t}$ is a total power, $B_{m}$ is the residual magnetic flux, $K_{f}$ is a waveform coefficient, $K_{u}$ is a window utilization factor, $f$ is the switching frequency, $J$ is a current density. The maximum window size of $A_{P}$ method must be made considering the space factor of coil, so that there is no interference between each other when the coil is winded inside the window. $A_{P}$ is proportional to $A_{c}$ and is inversely proportional to $f, B_{m}$, and $J$. That is, the volume of transformer core gets smaller when it is designed in high frequency and magnetic flux density [8]. Since the switching current through the IGBT flows in the transformer primary, $A_{P}$ must be designed with about $10 \%$ margin [9]. Figure 2 shows the inverter arc welding machine system.

\subsection{Parallel Circuit}

The winding method using parallel circuit is as in Fig. 3. $X$ represents the start point of coil and $X^{\prime}$ represents the end point of coil. In the primary size, AA' and BB' are connected in series. The $\mathrm{CD}$ of secondary winding coil is coiled in the forward direction and EF is coiled in the reverse direction. Also, coil $\mathrm{C}$ is connected to $\mathrm{F}$ and $\mathrm{D}$ is connected to $\mathrm{E}$, thereby making a total of 2 parallel circuits. C'D'E'F' are connected together. Since the secondary winding coil has low voltage and high current $(77 \mathrm{~V}, 389 \mathrm{~A})$, the current is divided into two through 2 parallel circuits and thus the current density is halved [10].

\subsection{PSP Winding and the Sheet Coil}

PSP winding method and sheet coil are used to reduce
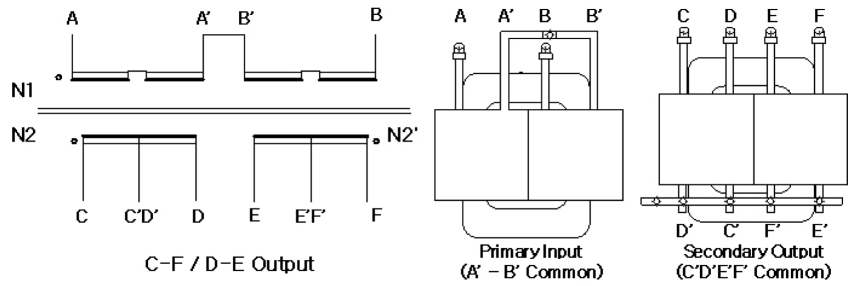

Fig. 3. Winding Method using Parallel Circuit.

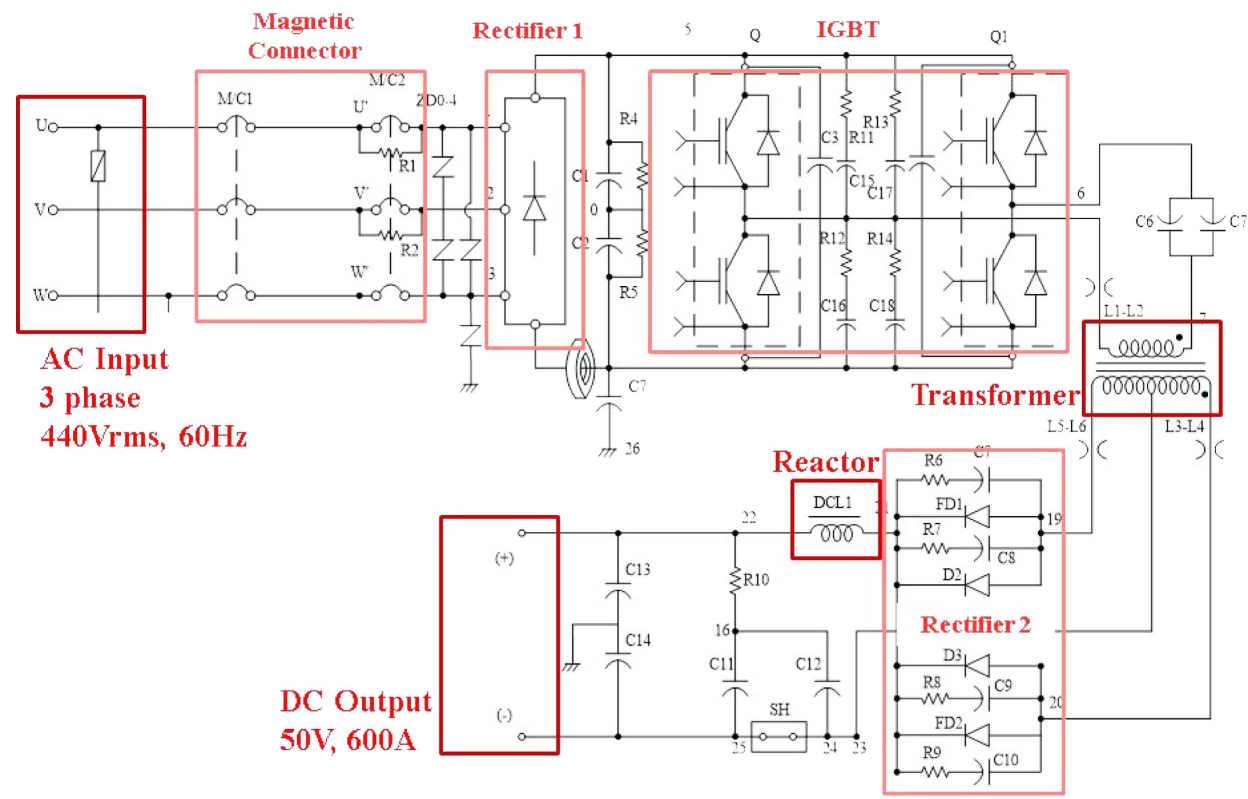

Fig. 2. (Color online) Overview of Inverter Arc Welding Machine System. 


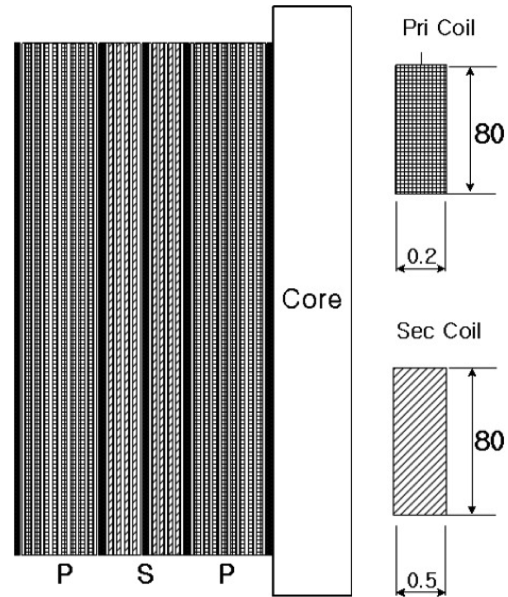

Fig. 4. PSP Winding Method and Sheet Coil.

the influence of proximity effect and skin effect.

$$
\delta=\frac{1}{\sqrt{\pi f \mu \sigma}}
$$

$\mu$ is a permeability of the coil, $\sigma$ is a conductivity of the coil.

The skin depth $\delta$ of coil from formula 3 is $0.554 \mathrm{~mm}$, and a coil much thinner than skin depth must be used (Primary coil is $0.2 \mathrm{~mm}$, Secondary coil is $0.5 \mathrm{~mm}$ ). In addition, in the high frequency band by the proximity effect, the size and status of current changes greatly depending on the location of the two parallel coils of secondary winding. Therefore, the parallel coil of secondary winding must be interleaved with the primary coil and have the same locations. Such placed parallel coil have the same magnetic flux and magnetic field distribution around it and prevents current unbalance [11]. As a result, PSP and SPS coil, not PS or SP coil, must be used. Figure 4 shows the PSP coil method and Fig. 5 shows the specifications of transformer designing.

The two coil methods in Fig. 6 represents the layer coil and sheet coil, and both methods have the same current density. The two models operate for an hour and their
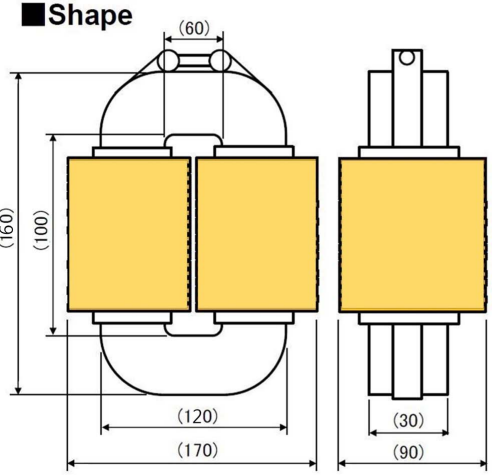

Design parameter Circuit : Full bridge converter Power : 30kVA SW frequency: $14.4 \mathrm{kHz}$ Input: 560VDC(AC440V) Output:50VDC 600A Flux swit: Flux swing : $\mathrm{Bm}=0.6 \mathrm{~T}$

Coil details Core shape

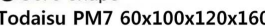
-Primary winding $0.2 \mathrm{~mm} \times 80 \mathrm{~mm} \times 32$ Turns

- Secondary winding $0.5 \mathrm{~mm} \times 80 \mathrm{~mm} \times 4$ Turns

Fig. 5. (Color online) Specifications of Transformer Designing.

temperature saturation was confirmed. Copperplate coil and the coil method of PSP model were used based on the result of Fig. 6.

\subsection{Comparison according to Core Materials}

To minimize the optimum of the same allowable fre-
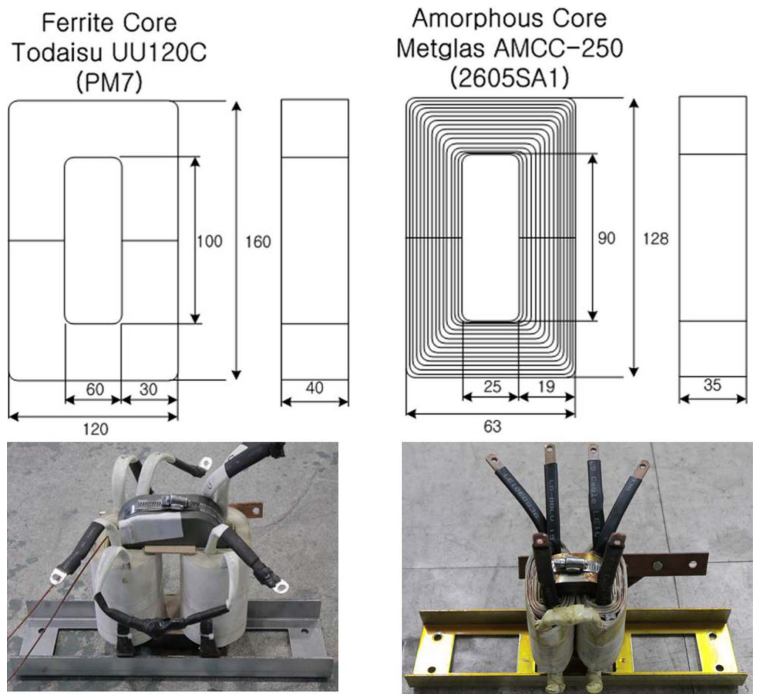

Fig. 7. (Color online) Transformer made by using Ferrite and Amorphous Core.

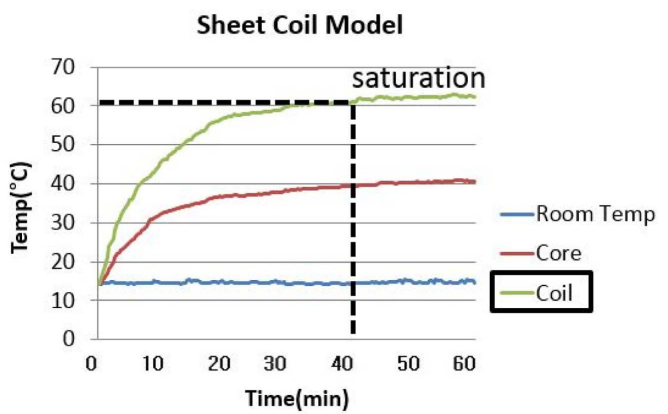

Fig. 6. (Color online) Temperature Saturation Curve in the Layer Coil and Sheet Coil Model. 
Table 1. Specifications of the Ferrite and Amorphous Core of Transformer.

\begin{tabular}{ccc}
\hline \hline Value & $\begin{array}{c}\text { Ferrite } \\
\text { Core TR } \\
\text { (PM7) }\end{array}$ & $\begin{array}{c}\text { Amorphous } \\
\text { Core TR } \\
\text { (AMCC-250) }\end{array}$ \\
\hline Core Weight $(\mathrm{kg})$ & 3.48 & 2.23 \\
Coil Weight $(\mathrm{kg})$ & 3.79 & 2.47 \\
Turn Ratio & $32: 4$ & $24: 3$ \\
Flux Density (T) & 0.11 & 0.45 \\
Switch Freq. (kHz) & 14.4 & 14.4 \\
Core Loss (W) & 56.84 & 57.32 \\
Coil Loss (W) & 20.22 & 10.11 \\
Efficiency (\%) & 97.74 & 96.96 \\
\hline
\end{tabular}

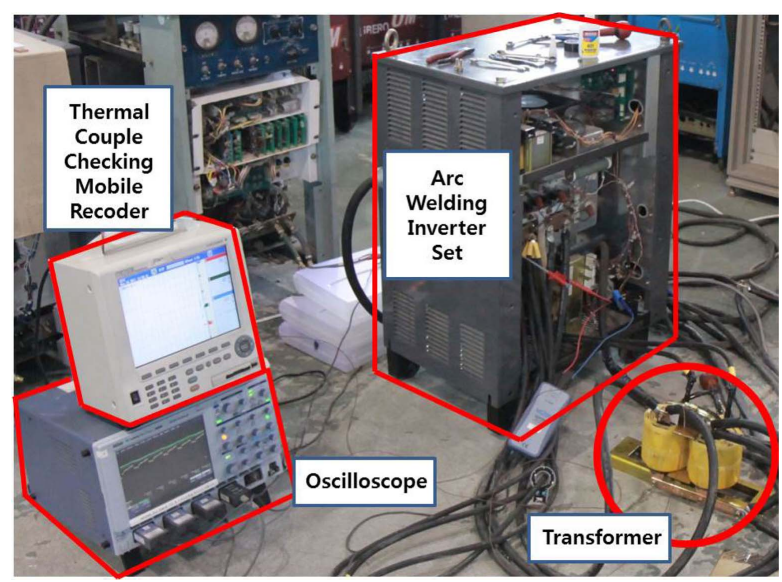

Fig. 8. (Color online) Experiment System of Arc Welding Machine.

quency, magnetic flux density needs to be higher. Therefore, the transformer was made with ferrite and amorphous core that can be used in a $14.4 \mathrm{kHz}$ section. The specifications of each transformer are as in Table 1 and Fig. 7.

Since the amorphous has a magnetic flux density that is three times higher than that of ferrite as in Table 1, it has lower weight and number of turns of coil within the same frequency. Amorphous is better in terms of performance, but it requires more precision in production than ferrite because multilayered core is made by molding powder due to the nature of amorphous production. The two models were applied inside the arc welding machine for the experiment and the output was satisfying. The experiment environment is as in Fig. 8.

\section{Air Gap Core Method}

A very high current flows inside a welding machine as its switch repeats shortening and opening. The output current of welding machine is as in Fig. 9. The time must

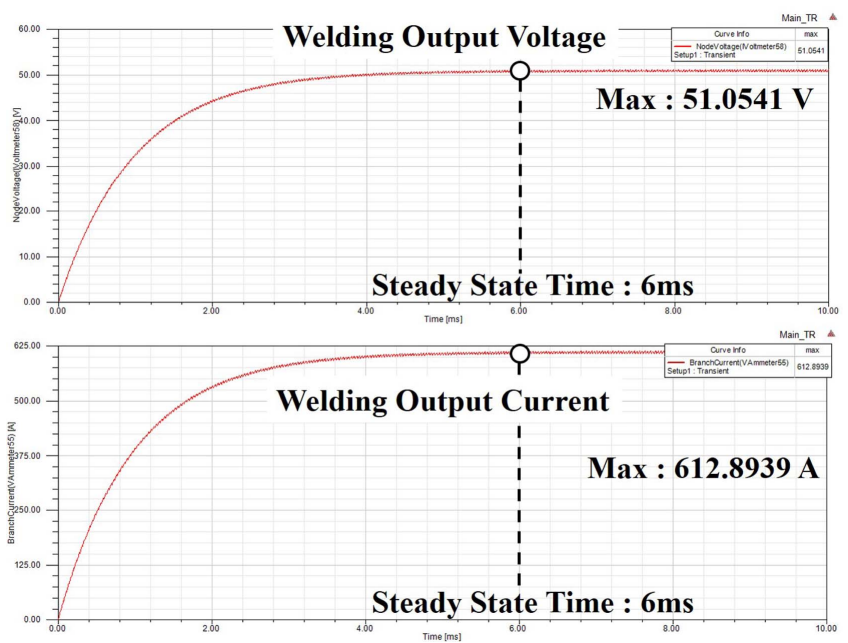

Fig. 9. (Color online) Output Voltage and Current Waveform during Load.

be more than $6 \mathrm{~ms}$ since shortened to satisfy the rated current at $600 \mathrm{~A}$ during the load.

The inrush current of transformer primary winding occurs when the load is connected to the secondary winding of transformer and the switch is on. During the rated load of welding machine, welding works normally after 5 ms. The maximum welding time must be within the allowable current of the switching element that the inrush current of primary winding can endure. If the maximum welding time is exceeded, the switching element is burned
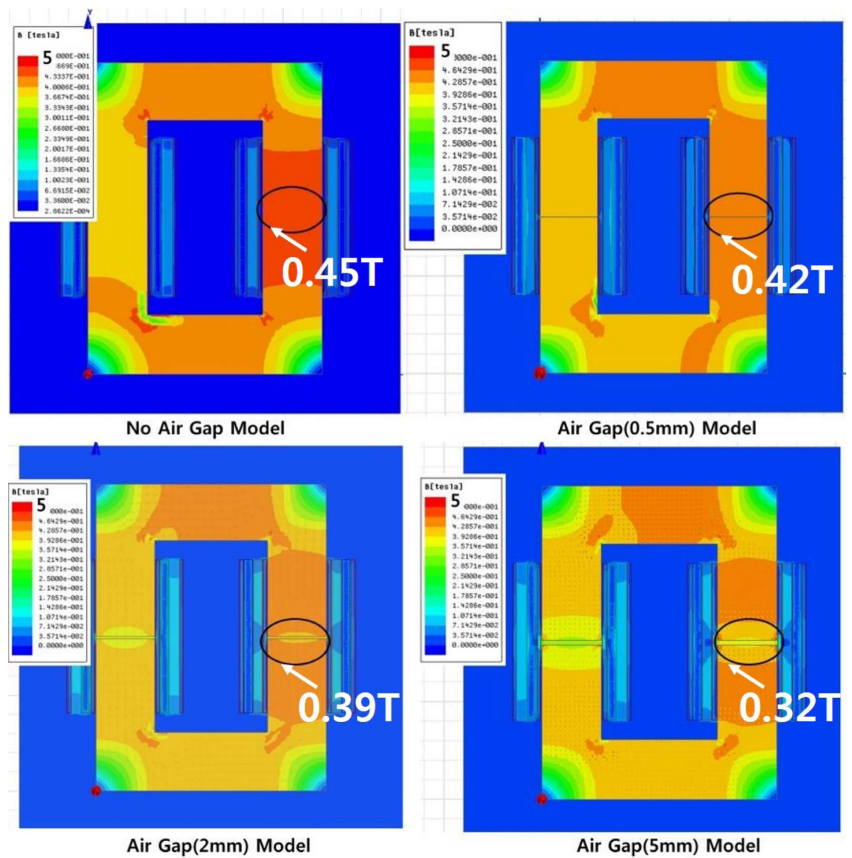

Fig. 10. (Color online) Comparison of Magnetic Flux Saturation according to Air Gap. 


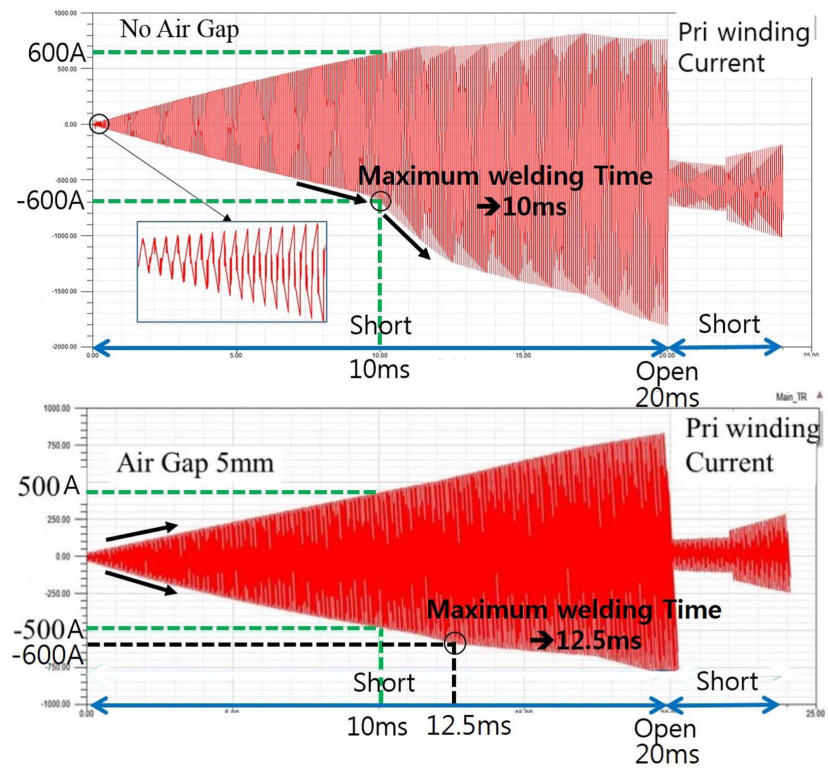

Fig. 11. (Color online) Comparison of the Waveform of Primary Winding Inrush Current according to Air Gap.

out $[12,13]$. An air gap $(0-5 \mathrm{~mm})$ was given to increase the maximum welding time. The inrush current of primary winding is decreased as the induced voltage becomes smaller by primary winding, since the inductance in the core drops when the air gap increases. However, if the air gap exceeds $5 \mathrm{~mm}$, the average magnetic flux density (amorphous $0.45 \mathrm{~T}$ ) decreases and cannot satisfy the rated output during load. The result of finite element analysis on the differences of air gap are as in Fig. 10.

The highest current that can flow in the used IGBT is $-600 \sim 600 \mathrm{~A}$. The characteristics of the inrush current of primary winding are as in Fig. 11. This waveform shows welding after the welding time was set up to $20 \mathrm{~ms}$ and switch open was made.

When the time gets above $12.5 \mathrm{~ms}$, the allowable current of IGBT is exceeded regardless of air gap. Thus, the maximum welding time cannot go beyond $12.5 \mathrm{~ms}$ in the used IGBT. The model without an air gap exceeds $-600 \mathrm{~A}$ at $10 \mathrm{~ms}$ of welding time, while a model with $5 \mathrm{~mm}$-air gap does not exceed $-600 \mathrm{~A}$ at $10 \mathrm{~ms}$ of welding time. This enables welding at up to $10 \mathrm{~ms}$. During welding, the output at load as well as the allowable current of IGBT and maximum welding time must be considered.

\section{Conclusion}

Since an inverter arc welding machine uses high frequency band, it has an advantage of reducing the size of transformer. It is necessary to reduce the size of trans- former core to save cost. However, when the size of core is decreased, magnetic flux is saturated and huge inrush current occurs by the primary winding of transformer. The huge inrush current of primary winding can make IGBT, the switching element, burn out. As a result, since the maximum welding time is proportional to the time of the safe operation of IGBT, the transformer was designed by inserting an airgap to decrease the inrush current of primary welding. It is necessary to appropriately choose the maximum length of air gap as it influences the output of load.

\section{Acknowledgment}

This work was supported by the Human Resources Program in Energy Technology of the Korea Institute of Energy Technology Evaluation and Planning (KETEP), granted financial resource from the Ministry of Trade, Industry \& Energy, Republic of Korea (No. 20154030200900).

This work was supported by the National Research Foundation of Korea (NRF) grant funded by the Korea government (Ministry of Science, ICT \& Future Planning) (No. NRF-2016R1A2A1A05005392).

\section{References}

[1] L. Zhao, C. F. Foo, and K. J. Tseng, IEEE Trans. Magn. 35, 3550 (1999).

[2] Z. Yu, J. L. Liu, X. B. Cheng, and H. Zhang, IEEE Trans. Plasma Science 38, 1019 (2010).

[3] N. H. Kutkut and D. M. Divan, IEEE Trans. Power Electronics 13, 202 (1998).

[4] P. Poulichet, F. Costa, and E. Laboure, IEEE Trans. Magn. 39, 998 (2003).

[5] Colonel Wm T. McLyman, Transformer and Inductor Design Handbook, CRC Press, 4th ed. (2011).

[6] J. D. Lavers and V. Bolborici, IEEE Trans. Magn. 35, 3541 (1999).

[7] I. G. Kim, S. Y. Cho, H. J. Park, C. Y. Park, S. H. Ham, and J. Lee, Proceeding of the 43th KIEE Annual Summer Conference, 450 (2012).

[8] C. Leung, S. Baek, S. Dutta, and S. Bhattacharya, Energy Conversion Congress and Exposition, 1551 (2010).

[9] R. Prochazka, J. Hlavacek, and K. Draxler, IEEE Trans. Magn. 51, Article 2800204 (2015).

[10] N. Y. Abed and O. A. Mohammed, IEEE Trans. Magn. 46, 3249 (2010).

[11] J. Cobos and R. Prieto, IEEE PELS Newsletter 4, 10 (2004)

[12] J. Faiz and S. Saffari, IEEE Trans. Magn. 46, 578 (2010).

[13] A. Bartel, T. Hulsmann, J. Kuhn, and R. Pulch, IEEE Trans. Magn. 50, Article 7011904 (2014). 